(2) Open Access Full Text Article

\title{
Hypnosis for the Management of Anxiety and Dyspnea in COPD: A Randomized, Sham-Controlled Crossover Trial
}

This article was published in the following Dove Press journal: International Journal of Chronic Obstructive Pulmonary Disease

\author{
Hernán Anlló (iD ${ }^{1,2}$ \\ Bertrand Herer ${ }^{1,3}$ \\ Agathe Delignières ${ }^{1,4}$ \\ Yolaine Bocahu',3 \\ Isabelle Segundo (D) 1,3 \\ Valérie Mach Alingrin ${ }^{1,5}$ \\ Marion Gilbert ${ }^{1,3}$ \\ François Larue ${ }^{1,5}$ \\ 'Clinical Hypnosis Research Team, Bligny \\ Hospital Center, Briis-sous-Forges, \\ France; ${ }^{2}$ Watanabe Cognitive Science \\ Laboratory, School of Fundamental \\ Science and Engineering. Waseda \\ University, Tokyo, Japan; ${ }^{3}$ Pneumology \\ Unit, Bligny Hospital Center, Briis-sous- \\ Forge, France; ${ }^{4}$ Counselling and \\ Psychological Care Unit, Bligny Hospital \\ Center, Briis-sous-Forge, France; \\ ${ }^{5}$ Palliative Care Unit, Bligny Hospital \\ Center, Briis-sous-Forge, France
}

Background: Patients with chronic obstructive pulmonary disease (COPD) are prone to dyspnea, increased respiratory rate and other anxiety-inducing symptoms. Hypnosis constitutes a complementary procedure capable of improving subjective feelings of anxiety.

Objective: Assessing the efficacy of a 15-minute hypnosis intervention for immediate improvement of anxiety in severe COPD patients.

Methods: Twenty-one participants, COPD patients (mean FEV1 <32.3\%), were randomly assigned to two individual sessions in crossover (sham and hypnosis, 24-h washout period, arms: hypnosis-sham $[n=11] /$ sham-hypnosis $[n=10])$. We tracked pre- and post-intervention anxiety (STAI-6 score) as primary endpoint.

Results: Nineteen (90.5\%) participants completed the study. Anxiety diminished significantly after hypnosis (STAI-6 scores $-23.8 \%$ [SD $=18.4 \%$ ] hypnosis vs $-3.1 \%$ [32.8\%] sham; $\chi^{2}=8, \mathrm{P}<0.01$, Bayes Factor 5.5). Respiratory rate also decreased after hypnosis. Improvements in $\mathrm{SpO} 2$ and Borg exertion scores were registered after both conditions.

Conclusion: A 15-minute hypnosis session improved participants' anxiety and lowered respiratory rate (as opposed to sham). Improvements in anxiety were correlated with an alleviation in respiratory strain. Results imply that hypnosis can contribute to the improvement of anxiety levels and breathing mechanics in severe COPD patients.

Registration Id: ISRCTN10029862.

Keywords: hypnosis, anxiety, depression, dyspnea, COPD, complementary care

\section{Introduction}

Chronic Obstructive Pulmonary Disease (COPD) is a highly prevalent and debilitating respiratory condition characterized by chronic airflow limitation, increased respiratory rate, dyspnea and other persistent respiratory symptoms. ${ }^{1,2}$ Growing evidence associates dyspnea to a higher risk of experiencing anxiety, depression and suicidality. ${ }^{3-5}$ In stable COPD, the prevalence of clinical depression ranges between $10 \%$ and $42 \%$, and prevalence of anxiety between $10 \%$ and $19 \%{ }^{6}$ A definitive causal link between these conditions can be hard to establish, as symptoms of depression, anxiety and COPD frequently overlap, and the etiology of the association between pathologies is unclear. ${ }^{3}$ However, treating these comorbidities in tandem with COPD is of central importance, as evidence has shown that the alleviation of anxiety symptoms can improve COPD prognosis and increase rehabilitation completion rates. ${ }^{3,7,8}$ The American Thoracic Society consensus statements on COPD of $1999^{9}$ have acknowledged that medical and pharmacological
Correspondence: Hernán Anlló Clinical Hypnosis Research Team, Bligny Hospital Center, Rue de Bligny, Briis-sousForges 91640 , France

Tel +33 I 69263000

Fax +33 I 69263090

Email hernan.anllo@cri-paris.org
International Journal of Chronic Obstructive Pulmonary Disease 2020:15 2609-2620 
treatments, when alone, are of limited efficacy for the relief of dyspnea and anxiety in people with advanced COPD. ${ }^{10,11}$ Psychological and complementary management of COPD has been strongly encouraged, and evidence in its favor has been promising so far. ${ }^{12-18}$ Furthermore, because of the interactions between anxiety, depression and chronic dyspnea, it has been proposed that proper assessment and comprehensive management of COPD could constitute a Human Rights matter, and psychological care together with well-informed choice of intervention should be a fundamental complement to standard treatment. ${ }^{11}$ The GOLD initiative for COPD recommends cognitive behavioral therapy and mind-body interventions (mindfulness-based therapy, yoga, relaxation and others) for managing anxiety and depression in patients with COPD. ${ }^{1,2}$ However, despite its numerous advantages (ie, immediate effect, easy and fast implementation, virtually no effort required on behalf of the patient) the efficacy of hypnosis for COPD complementary anxiety management has not yet been evaluated.

Growing scientific evidence supports the use of hypnosis for pain and suffering management in severe chronic diseases. ${ }^{19}$ For example, hypnosis-based psychodynamic treatments have been found effective in improving anxiety and depression scores in amyotrophic lateral sclerosis, which severely impairs respiratory function. ${ }^{20}$ The main benefits of incorporating hypnosis to the management of respiratory conditions have been generally identified as relief in the anxiety related to ventilation problems, alleviation of discomfort, and improvements in breathing regulation. ${ }^{17-19,21-23}$

Hypnotic suggestions typically elicit instant responses. $^{54,56}$ For example, it has been observed that hypnotic analgesia (ie, the suppression or mitigation of pain through hypnotic suggestion) sets in immediately after the hypnotic procedure. ${ }^{19,54,56}$ Hence, in the present study, we inquired whether COPD-related anxiety would also respond positively and immediately to the implementation of hypnosis. We set out to evaluate the transient effects of a scripted, 15-minute hypnosis session on severe COPD patients' anxiety levels, elaborated upon the experience of COPD symptoms. $^{24}$

Reliably testing hypnotic effects in a reproducible manner can be challenging, as hypnotic effects are known to depend on motivation and expectation. To control for these potential confounds, we incorporated a sham session to be administered in crossover, consisting of the same verbal, motor and social cues as hypnosis, but lacking hypnotic suggestions and an induction. Our primary hypothesis was that hypnosis (but not sham) would cause a decrease in anxiety scores. Together with anxiety, we tracked respiratory rate, peripheral oxygen saturation, and Borg's breathing exertion scores, to evaluate if any changes produced by the hypnotic intervention would have mechanical and physiological correlates relevant to respiratory quality.

\section{Methods}

\section{Design}

The following was a randomized, sham-controlled, crossover non-drug trial, conducted at the Bligny Hospital Center (CHB) in Briis-sous-Forges, France (ISRCTN \#10029862), from $01 / 09 / 2017$ to $20 / 02 / 2020$ (overall dates including initial planning, piloting and completion). The study was conducted in accordance with the ICH Guidelines for Good Clinical Practice, with applicable local regulations, and with the ethical principles as laid down in the Declaration of Helsinki (2008). All procedures were approved by the CHB internal Ethics Committee, as well as by the National Committee of People Protection (CPP) of Hotel Dieu Hospital, Ile-deFrance (national registration of the protocol: 07/11/2019, ethics approval number CPPIDF1-2019-ND75). Reporting was done in accordance with CONSORT guidelines for social and psychological interventions (see Consort Checklist in Supplementary Methods). All participants where inpatients at the Centre Hospitalier de Bligny. The trial's existence was communicated by a hospital representative to all in-patients who fell within the inclusion criteria.

Participants underwent two 15-minute individual interventions in crossover, hypnosis and sham, in randomly assigned order (arms: hypnosis-sham/sham-hypnosis), with a $24-\mathrm{h}$ washout period between interventions. The $15-$ minute duration was fixed a-priori, as it was identified by our team as the minimal duration needed to administer a complete hypnotic induction together with the selected hypnotic suggestions. While full therapeutic hypnosis sessions can last up to an hour or more, ${ }^{56}$ we saw this as impractical and hoped to create a compact, scripted intervention that could be easily integrated into existing complementary care. The size of the washout period was determined to be sufficient, as no evidence exists to date indicating that the effects of a single concrete hypnotic suggestion would linger beyond a few hours. ${ }^{54}$ Further 
analyses for carryover and period effects confirmed that the length of the washout period was sufficient (see Table $\underline{\mathrm{S} 2}$ in Supplementary Methods).

Randomization was performed by a hospital representative who had no prior contact with the participants, using a computer random number generator that assigned a numerical ID to each participant, ensuring that their identity would remain anonymous until intervention assignation. These anonymized participants were assigned through computer random permutation to a pair of investigators who would conduct the interventions and data collection. Permutation was programmed so that each arm would have nearly the same number of participants, and each pair of investigators would have nearly the same number of participants to interview.

A total of four pairs of investigators (medical practitioners specialized in psychology, pulmonology and/or palliative care, trained in hypnotherapy) were charged with administering both sessions (hypnosis and sham) and obtaining participant data. Since allocation was performed through computer permutation, researchers could not predict assignment of investigator or session order, nor could they change them. No prior clinical relationship existed between participants and medical practitioners.

\section{Participants}

The study included men $(n=13)$ and women $(n=8)$ with a clinical diagnosis of COPD and dyspnea, global initiative for obstructive lung disease (GOLD) spirometric stage 3 or worse, ${ }^{1,2}$ smoking history of $\geq 10$ pack-years, and post-bronchodilator forced expiratory volume in 1 second FEV1/FVC ratio of $<0.7$. Other key inclusion criteria were clinical stability, no participation in pulmonary rehabilitation in the 3 months before the study, and no previous experience with hypnosis. Exclusion criteria focused on conditions that would interfere with patients' responsiveness to verbal social interaction (ie, significant cognitive impairment, hypercapnic encephalopathy or confusional syndrome, deafness) or inability to comply with the hypnotic procedure (ie, mechanical ventilation during the session, psychotic pathology). Possible cognitive impairment was assessed at the time of admission by the Psychology Department of the Centre Hospitalier de Bligny. The complete list of inclusion and exclusion criteria is available in Supplementary Table S1, in the Supplementary Materials. Candidate initial assessment started on December 2019, and recruitment ended on
February 2020, when the planned number of participants was reached.

\section{Data}

Data were digitally stored ensuring patient anonymity, in conformity with EU General Data Protection Regulation (GDPR). The investigators in charge of data analysis were given access to the anonymous digital version of the data and were blinded to treatment allocation. All participants provided written informed consent before enrollment. Participants were free to withdraw from the study at any time.

\section{Procedure}

All participants were visited while at rest. Interventions were conducted in the patient's room and while the patient was in bed, to control for conditions such as environment and body position. When addressing the participants, interventions were identified as "Attention exercises". The hypnosis session was further described as "hypnosis", and the sham was further described as "an exercise of active listening". Interventions lasted for 15 minutes and were separated by a washout period of $24 \mathrm{~h}$. Both interventions were presented as equally relevant, as to prevent prior differences in compliance or motivation. For the same reason, no statements regarding possible differential therapeutic effects between interventions were made.

Both sessions were administered in an identical manner and required the same motor and communication responses from the patient (ie, concentrate on the practitioner's voice, eye closure, relaxation, nodding). For hypnosis, patients were asked to concentrate in nature-themed metaphors and hypnotic suggestions of pure air entering their lungs; for sham, they were asked to concentrate on the content of a nature-themed opinion piece that was read to them, and imagine the scenes described therein (see Annex S1 in the online supplement for the full version of both scripts - English and French versions available).

The hypnosis script for the treatment intervention was developed respecting all recommended security guidelines. $^{48,49}$ While hypnosis is considered a risk-free process with few contraindications, ${ }^{48}$ we avoided ageregression techniques ${ }^{48,49}$ and asking personal questions that could lead to the fabrication of pseudomemories. ${ }^{59} \mathrm{We}$ also refrained from utilizing any kind of allusion to negative emotions, distressing events or physically 
uncomfortable sensations and kept the session purposefully short as not to fatigue the participants. ${ }^{60}$

\section{Outcome Measures}

The following demographic data were recorded at initiation of the study: age, sex, smoking status, and regular use of oxygen. COPD was classified according to the severity of airflow limitation (Global Initiative for Chronic Obstructive Lung Disease [GOLD] stages 1-4) and based on symptoms, dyspnea, spirometric classification, and risk of exacerbations (GOLD stages A-D). We also recorded body mass index (BMI), spirometry results (FVC, FEV1, and FEV1/FVC), and 6-minute walk test results (6MWT).

Outcome measures were obtained as follows. Anxiety scores were measured through the State-Trait Anxiety Inventory-6 questionnaire (STAI-6; 25), a high-reliability 6-item version of the original State-Trait Anxiety Inventory questionnaire (STAI; ${ }^{26,27}$ ). The STAI measures via self-report the current presence and severity of anxiety symptoms, as well as anxiety propensity. Current in-situ anxiety assessment utilizes items that probe subjective feelings of worry, tension and arousal (STAI-S). The questionnaire poses 20 questions to be answered through a Likert-like scale, producing a final score ranging between 20 and 80 points. The cutoff score for a clinical anxiety diagnosis is 39 points. ${ }^{61}$ In order to render our intervention as short as possible without compromising measurement quality, we utilized the STAI-6 version of the scale. ${ }^{25}$ This six-item shortened inventory has been shown to reliably reproduce the STAI-S anxiety assessment with little to no precision loss, in a fraction of the duration. ${ }^{25}$

As a proxy for dyspnea, we measured respiratory rate (RR cycle/min) and arterial oxygen saturation (SpO2, \%). Respiratory rate ${ }^{28}$ was measured in cycles per minute, with the help of a digital chronometer. Blood oxygen saturation $^{29}$ was measured with a pulse oximeter. Borg scores for respiratory strain were obtained with a visual analog scale. ${ }^{30}$ Difference in STAI-6 score before and after intervention was identified as delta STAI-6 ( $\triangle$ STAI-6), as were differences in $\mathrm{RR}(\Delta \mathrm{RR}), \mathrm{SpO} 2(\Delta \mathrm{SpO} 2)$, and Borg score $(\Delta \mathrm{Borg})$.

Baseline scores for all measurements were obtained after a 2-minute period of non-guided relaxation; outcome scores were measured immediately after intervention. The primary outcome for this study was determined by assessing differences in anxiety before and after each intervention, as well as differences in $\triangle$ STAI-6 between interventions. All other outcomes were deemed as secondary outcomes.

\section{Statistical Methodology Statistical Analyses}

We performed data analysis using $\mathrm{R} .{ }^{31}$ We considered the differences between baseline and outcome scores for anxiety ( $\triangle \mathrm{STAI}-6)$, respiratory rate $(\triangle \mathrm{RR})$, oxygen saturation $(\Delta \mathrm{SpO} 2)$ and Borg scale $(\Delta \mathrm{Borg})$, for sham and hypnosis interventions. We also contrasted these differences across interventions (sham vs hypnosis). Indicators were modeled by implementing linear (mixed) models, with a random intercept per participant. ${ }^{32,33}$ We chose a hierarchical modeling approach in order to account for individual participant differences, and for imbalances in sample size across factors and levels. ${ }^{34,35}$ Hence, we first modeled STAI-6, $\mathrm{RR}, \mathrm{SpO} 2$ and Borg score against Observation Time (a categorical factor with levels: "Baseline", "Outcome"). Then, to assess if sham and hypnosis were significantly different from each other, we modeled $\Delta$ STAI-6, $\Delta R R$, $\Delta \mathrm{Borg}$ and $\Delta \mathrm{SpO} 2$ by regressing them against Intervention Type (a categorical factor with levels: "Hypnosis", "Sham").

We performed significance tests by means of likelihood ratio tests that compared our models to simpler models, in which the relevant predictor was removed (null model). ${ }^{36,37}$ ANOVA tables were computed through Analysis of Deviance (Type II Wald $\chi^{2}$ test), and post hoc pairwise comparisons through Tukey contrasts of least-squares means, setting a $0.95 \mathrm{CI}$ (car and lsmeans $\mathrm{R}$ packages, see $\mathrm{s}^{37,38}$ ). Findings were considered statistically significant when $P$ value was $<0.05$.

To prove lack of effect at a given contrast, we calculated an approximation of the Bayes Factor from the Bayesian Information Criterion, for the saturated and null models originally implicated in the contrast (BIC approximation to $\mathrm{BF}$, so that $\mathrm{BF}=\exp ((\mathrm{BICnull-BICfull}) / 2))$. The $\mathrm{BF}$ hence indicated the strength of evidence in favor of the full model, meaning $\mathrm{BF}<1$ equaled virtual lack of effect, and BF $>2$ equaled a strong, noteworthy effect. ${ }^{39,40}$

Simulation-based power analysis for the primary outcome showed that for a sample of $n=19$, a regression analysis with a significance level of $5 \%$ had a power of $79 \%(95 \% \mathrm{CI}=76,81)$ for detecting a $-20.7 \%$ difference between post-hypnosis and post-sham mean $\Delta$ STAI-6 scores. See Supplementary Methods for power a detailed 
account of power analyses; see Supplementary Table S2 for carryover and period effects analyses details.

\section{Results}

\section{Participants}

At the time of admission, the study population had a mean age of 66.2 years $(\mathrm{SD}=9.58)$, Caucasian $(100 \%)$ with a mean BMI of $24.2 \mathrm{~kg} / \mathrm{m} 2(\mathrm{SD}=5)$, and a mean forced expiratory volume in $1 \mathrm{~s}$ (FEV1) of $<32.1 \%$ predicted, SD $=13.3$. Mean BODE index score was $6.05(\mathrm{SD}=1.5)$. No significant differences were found for these baseline characteristics. Complete patients' clinical characteristics can be found in Table 1.

During the study period, 21 patients were randomized (hypnosis-sham: 11; sham-hypnosis: 10) and 19 finished the study (90.5\%; hypnosis-sham: 11; sham-hypnosis: 8 ). Reasons for failing to finish the study included withdrawn consent $(\mathrm{n}=1)$, and technical difficulties that prevented us from registering the data $(\mathrm{n}=1)$. The CONSORT flowchart for this study is presented in Figure 1A. Details on how the interventions where administered can be found in Figure 1B and $\mathrm{C}$.

Table I Baseline Characteristics of Participants

\begin{tabular}{|c|c|c|}
\hline $\begin{array}{l}\text { Baseline } \\
\text { Data }\end{array}$ & $\begin{array}{l}\text { Hypnosis - Sham } \\
(n=I I)\end{array}$ & $\begin{array}{l}\text { Sham - Hypnosis } \\
(n=10)\end{array}$ \\
\hline Age, years & $64.9(11.6)$ & $67.8(6.65)$ \\
\hline Men/Women & $6 / 5$ & $7 / 3$ \\
\hline $\mathrm{CCl}$ & $4.27(1.95)$ & $3.33(1)$ \\
\hline BMI, $\mathrm{kg} / \mathrm{m}^{2}$ & $25(6.20)$ & $23.19(2.99)$ \\
\hline FVC, \% pred & $69.2(16.2)$ & $65.3(23.2)$ \\
\hline $\mathrm{FEV}$, $\%$ pred & 33.5 (9.19) & $30.3(18.04)$ \\
\hline $\mathrm{FEV}_{\mathrm{I}} / \mathrm{FVC}$ & 45.1 (9.53) & $37(9.31)$ \\
\hline BODE Index & $6.2(1.23)$ & $5.88(I .8 I)$ \\
\hline 6MWT, m & $258(104)$ & 284 (81.91) \\
\hline mMRC score & $3.09(0.54)$ & $2.67(0.9)$ \\
\hline $\mathrm{PaO}_{2}$ & $70.4(13)$ & 72.2 (II.I) \\
\hline $\mathrm{PaCO}_{2}$ & $45(6.06)$ & $47.2(7.67)$ \\
\hline GOLD (I-4/ & 4/D (45.5\%) & 4/D (70\%) \\
\hline \multirow[t]{3}{*}{ A-D) } & $3 / D(45.5 \%)$ & 4/B (5\%) \\
\hline & 3/B (9\%) & $3 / D(20 \%)$ \\
\hline & & $3 / B(5 \%)$ \\
\hline
\end{tabular}

Note: Data presented as mean (SD).

Abbreviations: CCl, Charlson Comorbidity Index; 6MWD, 6-minute walk distance; BMI, body mass index; FEVI, forced expiratory volume in Is; FVC, forced vital capacity; FEVI/FVC, Tiffeneau score; BODE Index, BODE composite score for gravity assessment; mMRC score, Modified Research Council Questionnaire; $\mathrm{PaO}_{2}$, oxygen partial arterial pressure; $\mathrm{PaCO}_{2}$, carbon dioxide partial arterial pressure; GOLD, Global Initiative for Obstructive Lung Disease 2006 and 20I I criteria; SD, standard deviation.

\section{Primary Outcome}

A statistical and quantitative summary for differences between baseline and outcome for all measures can be found in Table 2. Differences between interventions (hypnosis vs sham) are reported in Table 3.

Anxiety, assessed through STAI-6 scores, decreased a mean percentage of (standard deviation [SD]) $-23.8 \%$ [18.4] after the hypnosis session $\left(\chi^{2}=28, \mathrm{DF}=1, \mathrm{P}<\right.$ $0.0001, \mathrm{BF}=1212$ ), equivalent to an 11.2 [9.2] point reduction in STAI-6 score (Figure 2A). The sham session, on the other hand, induced a non-significant STAI-6 score decrease of $-3.1 \%$ [32.8] $\left(\chi^{2}=2, \mathrm{DF}=1, \mathrm{P}=0.18, \mathrm{BF}=\right.$ $0.4)$. The difference in anxiety improvement between hypnosis and sham was itself significant $\left(\chi^{2}=8, D F=1, P<\right.$ $0.01, \mathrm{BF}=5.5)$ (Figure 2B). These results confirmed that hypnosis was effective for producing an immediate transient decrease in anxiety levels.

\section{Secondary Outcomes}

Decreases in Borg score portrayed a relief in respiratory strain, while decreases in STAI-6 scores reflected a relief of anxiety. To evaluate the link between these two subjective measures, we regressed $\triangle \mathrm{STAI}-6$ against $\Delta \mathrm{Borg}$ (Figure $2 \mathrm{C}$ ) and observed that both indexes were positively correlated, independently of intervention type (Model: $\triangle$ STAI-6 $\sim \Delta$ Borg $\mathrm{x}$ Intervention Type $+\varepsilon$. Main effects: $\Delta$ Borg, $\chi^{2}=5, \mathrm{DF}=1, \mathrm{P}<0.05$; Intervention Type, $\quad \chi^{2}=5, \quad \mathrm{DF}=1, \quad \mathrm{P}<0.05 ; \quad$ interaction $\quad \Delta \mathrm{Borg}$ $\mathrm{x}$ Intervention Type, $\chi^{2}=1, \mathrm{DF}=1, \mathrm{P}=0.32$ ). This correlation suggested that anxiety improvement was positively associated with relief in respiratory strain.

Oxygen saturation and respiratory rate were affected differently by hypnosis and sham. In order to better understand the impact of hypnosis over oxygen saturation levels and respiratory rate, we regressed $\triangle \mathrm{RR}$ against $\triangle \mathrm{SpO} 2$ across conditions (Figure 2D). We found that increases in oxygen saturation were significantly correlated with increases in respiratory rate for sham, but not for hypnosis (Model: $\Delta \mathrm{RR} \sim \Delta \mathrm{SpO} 2 \mathrm{x}$ Intervention Type $+\varepsilon$. Main effects: Intervention Type, $\chi^{2}=31, \quad \mathrm{DF}=1, \mathrm{P}<0.0001$; $\triangle \mathrm{SpO} 2, \quad \chi^{2}=25, \quad \mathrm{DF}=1, \quad \mathrm{P}<0.0001 ;$ interaction $\Delta \mathrm{SpO} 2$ $\mathrm{X}$ Intervention Type, $\chi^{2}=22, \mathrm{DF}=1, \mathrm{P}<0.01$ ). The fact that $\mathrm{SpO} 2$ levels would increase without an acceleration of $\mathrm{RR}$ for the hypnosis condition suggests that hypnosis could have contributed to an optimization of breathing mechanics.

Respiratory rate (cycle/min) decreased $-9 \%$ [13.6] after hypnosis, which translated to a 2 [2.87] point 
A

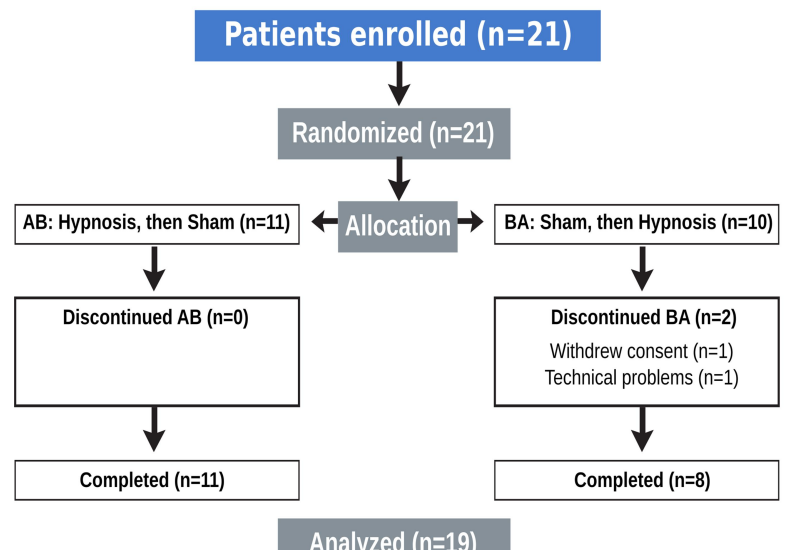

\section{Analyzed (n=19)}

B

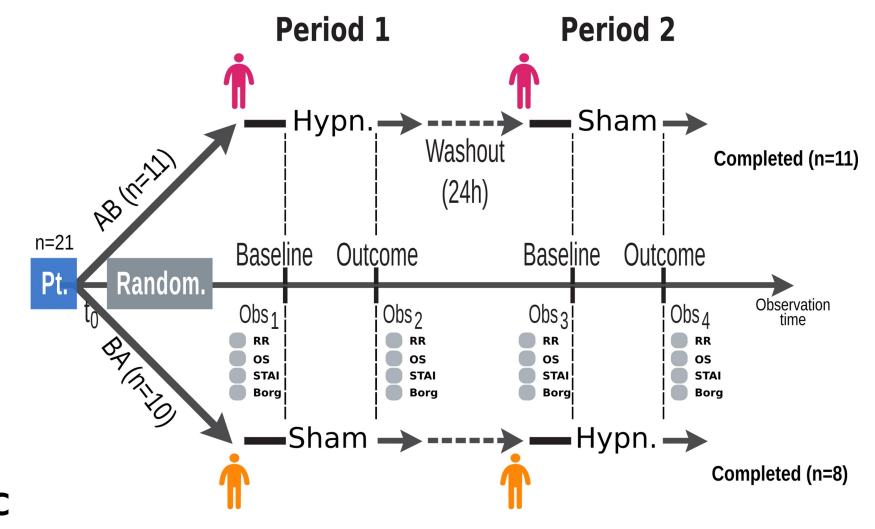

C

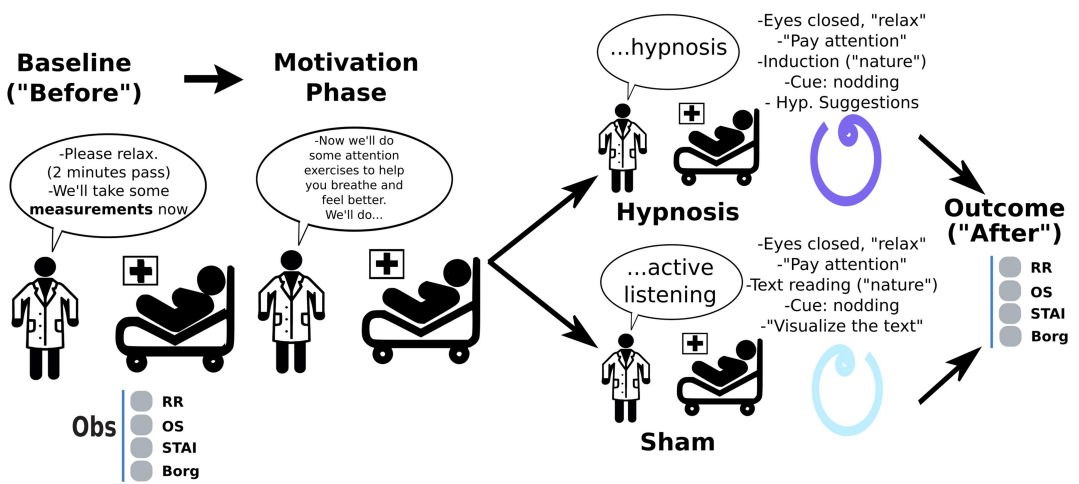

Figure I CONSORT chart and study design. (A) CONSORT flowchart. After screening and preselecting all CHB admitted patients, $2 \mathrm{I}$ patients were recruited and randomly assigned to one of four pairs of investigators, in charge of administering the sessions and collecting the data. Investigators were all psychologists, pneumonologysts and/or palliative care health practitioners, trained in hypnosis. Session order was counterbalanced across pairs of investigators. Of 21 patients, 2 failed to complete the trial (I for consent withdrawal, I for technical issues). (B) Outline. Detailed outline showing the observation time and collected measures. (C) Outline of Hypnosis and Shamcontrolled interventions. Interventions were scripted, of equal duration, and controlled for environment and body posture. Sessions were introduced as "Attention exercises" during the motivation phase. Hypnosis was then identified as "Hypnosis", and Sham was identified as "Active listening exercise". Both interventions were controlled for differences in expectation and motivation.

decrease in rate $\left(\chi^{2}=9, \mathrm{DF}=1, \mathrm{P}<0.01, \mathrm{BF}=8\right)$. The sham intervention produced a non-significant $+9.63 \%[30.6]$ increase $\left(\chi^{2}=0.3, \mathrm{DF}=1, \mathrm{P}=0.56, \mathrm{BF}=0.2\right)$. Effects of the hypnosis and sham sessions were significantly different $\left(\chi^{2}=7, \mathrm{DF}=1, \mathrm{P}<0.01, \mathrm{BF}=3.5\right)$ (Figure $\left.\mathrm{S} 1 \mathrm{~A}\right)$.

$\mathrm{SpO} 2(\%)$ increased $+2.74 \%$ [2.68] from baseline after hypnosis $\left(\chi^{2}=13, \mathrm{DF}=1, \mathrm{P}<0.001, \mathrm{BF}=29\right)$, and $+1.95 \%$ [3.19] after sham $\left(\chi^{2}=4, \mathrm{DF}=1, \mathrm{P}<0.05, \mathrm{BF}=1.3\right)$. For $\triangle \mathrm{SpO} 2$, interventions were not significantly different $(\mathrm{P}=0.36, \mathrm{BF}=0.25)$ (Figure $\mathrm{S} 1 \mathrm{~B})$.

Borg respiratory exertion scores also improved after both hypnosis and sham interventions, decreasing 1.5 points [1.7] after Hypnosis $\left(\chi^{2}=16, \mathrm{DF}=1, \mathrm{P}<0.0001, \mathrm{BF}=60\right)$ and 1.2 [1.4] after sham $\left(\chi^{2}=13, \mathrm{DF}=1, \mathrm{P}<0.001, \mathrm{BF}=24\right)$. For Borg scores as well, difference between sessions was not significant $\left(\chi^{2}=0.7, \mathrm{DF}=1, \mathrm{P}<0.4, \mathrm{BF}=0.3\right)$ (Figure $\left.\mathrm{S} 1 \mathrm{C}\right)$

In all, results indicated that, in patients with severe COPD and dyspnea, the use of hypnosis led to a significant immediate reduction of anxiety, as represented by a decrease in STAI- 6 scores. We also observed that this transient change in anxiety was accompanied by significant slowing of respiratory rate, increases in oxygen saturation and a decrease in Borg scores.

\section{Impact of Dropped Participants}

It was not possible to contrast our dataset against a complete version of the dataset including the two dropped participants, because data from the dropped participants were not available for analysis. In one case $(n=1)$, because a technical error prevented us from registering the data. In the other $(\mathrm{n}=1)$, because the participant withdrew their consent, rendering us unable to analyze their results.

\section{Discussion}

Dyspnea is a polymorphic multidimensional and undermining experience for which all health professionals 





Table 3 Differences Between Hypnosis and Sham Effects Over Anxiety, Respiratory Rate, Oxygen Saturation and Borg Score

\begin{tabular}{|c|c|c|c|c|c|c|c|}
\hline & & Hypnosis & Sham & $\chi^{2}$ & $\begin{array}{l}\text { Degrees of } \\
\text { Freedom }\end{array}$ & $P$ value & $\begin{array}{l}\text { Bayes Factor } \\
\text { (from BIC) }\end{array}$ \\
\hline \multirow[t]{4}{*}{$\begin{array}{l}\text { Model: } \sim \text { Intervention Type }+\mathcal{E} \text { (levels: } \\
\text { Hypnosis, Sham) }\end{array}$} & $\begin{array}{l}\triangle \text { STAI-6 }(\% \text { of } \\
\text { change) }\end{array}$ & $\begin{array}{l}-23.8 \\
(18.4)\end{array}$ & $\begin{array}{l}-3.11 \\
(32.8)\end{array}$ & 8 & I & $<0.01$ & 5.5 \\
\hline & $\begin{array}{l}\Delta \mathbf{R} \mathbf{R}(\% \text { of } \\
\text { change) }\end{array}$ & $-9(13.6)$ & $\begin{array}{l}+9.63 \\
(30.6)\end{array}$ & 7 & I & $<0.01$ & 3.5 \\
\hline & $\begin{array}{l}\Delta \mathrm{SpO}_{2},(\% \text { of } \\
\text { change) }\end{array}$ & $\begin{array}{l}+2.74 \\
(2.68)\end{array}$ & $\begin{array}{l}+1.95 \\
(3.19)\end{array}$ & 0.86 & I & 0.36 & 0.3 \\
\hline & $\begin{array}{l}\Delta \text { Borg (score } \\
\text { change) }\end{array}$ & $-1.5(1.7)$ & $\begin{array}{l}-1.2 \\
(1.4)\end{array}$ & 0.7 & I & 0.4 & 0.3 \\
\hline
\end{tabular}

Notes: Data presented as mean (SD). Percentage of change from baseline in STAl-6, respiratory rate (RR), oxygen saturation (SpO 2 ) and Borg scores, after Hypnosis and Sham interventions. Analysis of Deviance (Type II Wald $\chi^{2}$ test) showed that Hypnosis effects were significantly different from Sham effects for $\Delta$ STAI-6 and $\Delta R R$, but not for $\Delta \mathrm{SpO} 2$ and $\Delta$ Borg. $\Delta \mathrm{STAl}-6 / \Delta \mathrm{RR} / \Delta \mathrm{SpO}_{2} / \Delta \mathrm{Borg}=$ percentual mean difference from baseline after intervention (except for Borg, where difference is expressed in points); Intervention Type = predictor with factor levels: "Hypnosis", "Sham"; $\varepsilon=$ random effects (participant); BIC = Bayesian Information Criterion; BF = Bayesian Information Criterion Approximation to the Bayes Factor.

share a common responsibility, ie, the alleviation of symptoms through a comprehensive management of the disease. $^{41,42}$ Our study evaluated the efficacy of a rapid, scripted hypnotic intervention on four fundamental physiological and psychological indexes associated with COPD: respiratory rate (RR), arterial oxygen saturation

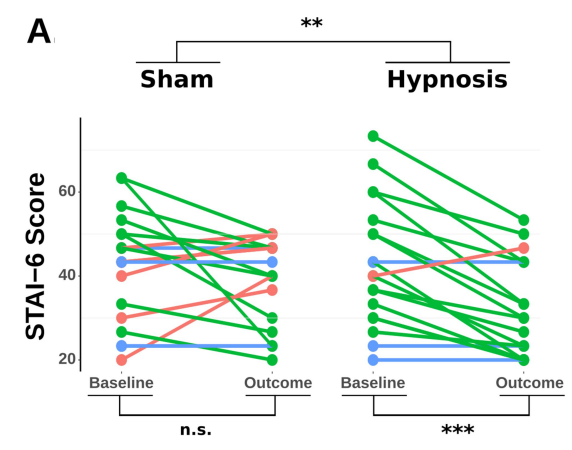

B
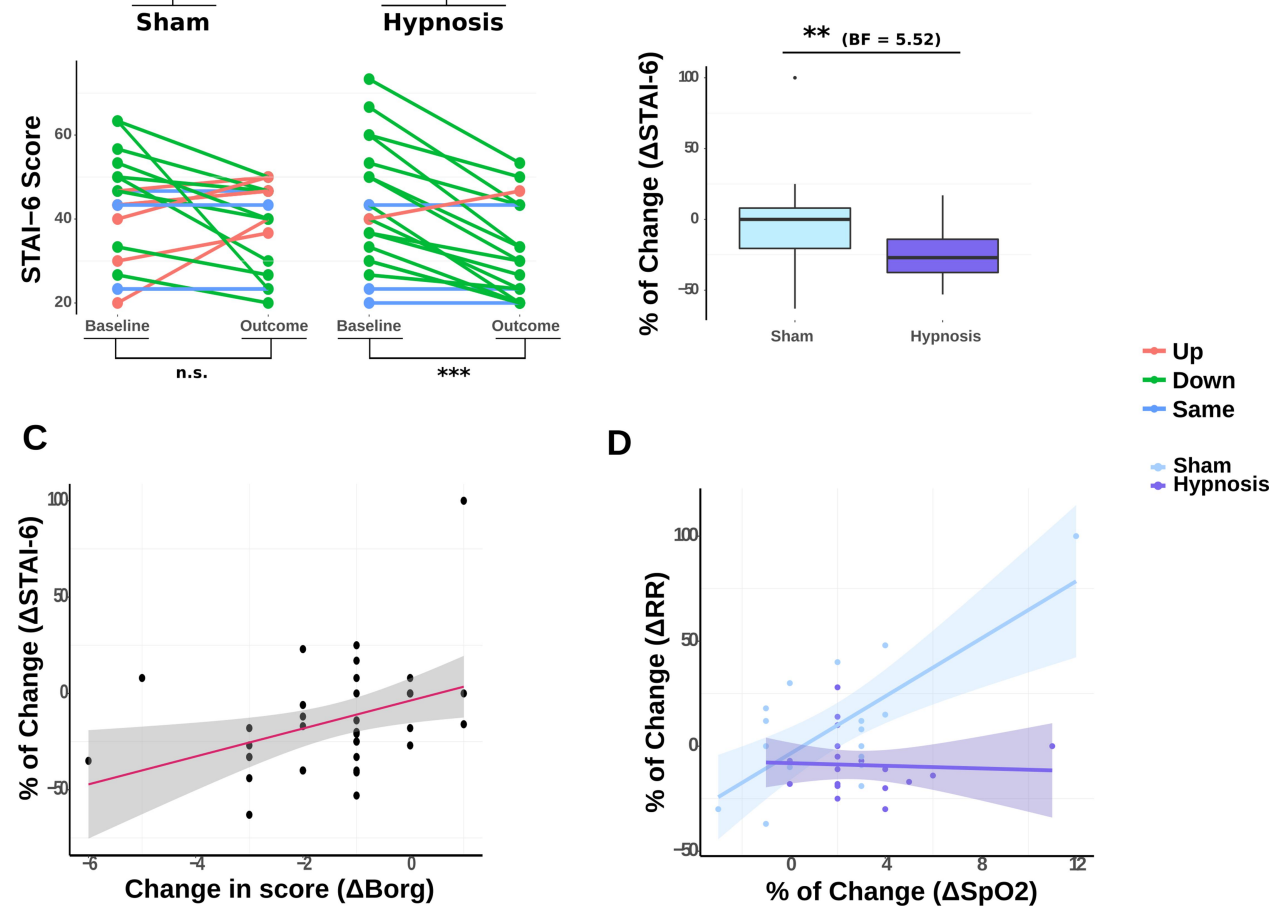

Figure 2 Summary of main hypnosis and sham effects. (A) STAI-6 before and after intervention. (A). STAI-6 scores. Changes in anxiety after sham and hypnosis sessions. Anxiety decreased significantly after hypnosis $(P<0.0001, B F=1212)$, but not after sham $(P=0.18, B F=0.4)$. (B) $\triangle S T A I-6$ across sessions. Outcome of the hypnosis session (mean \% of change $=-23.8 \%, S D=18.4)$ was significantly different from sham (mean \% of change $=-3.11 \%, S D=32.8)(P<0.01, B F=5.5)$. $(C)$. $\Delta S T A I-6$ regressed against $\Delta B$ Borg across conditions. Indexes were positively correlated, independently of intervention type, implying that improvements in anxiety were positively associated with relief in respiratory strain (main effect $\Delta \mathrm{B}$ org, $\chi^{2}=5$, DF=I, $\mathrm{P}<0.05$; main effect Intervention Type, $\chi^{2}=5, \mathrm{DF}=\mathrm{I}, \mathrm{P}<0.05$; interaction $\Delta \mathrm{B}$ org $\times$ Intervention Type, $\chi^{2}=1, \mathrm{DF}=\mathrm{I}, \mathrm{P}=0.32$ ). (D) $\triangle \mathrm{RR}$ regressed against $\triangle \mathrm{SPO} 2$ across conditions. $\mathrm{SpO} 2$ levels increased after both hypnosis and sham interventions, but were associated with increases in $\mathrm{RR}$ only after sham (main effects Intervention Type, $\chi^{2}=3 \mathrm{I}, \mathrm{DF}=\mathrm{I}, \mathrm{P}<0.000 \mathrm{I}$; main effect $\Delta \mathrm{SpO} 2, \chi^{2}=25, \mathrm{DF}=\mathrm{I}, \mathrm{P}<0.000 \mathrm{I}$; interaction $\Delta \mathrm{SpO} 2 \times$ Intervention Type, $\chi^{2}=22, \mathrm{DF}=\mathrm{I}, \mathrm{P}<0.0 \mathrm{I}$ ). (Significance thresholds: $* * P<0.01 ; * * * P<0.0001$ ). 
(Sp02), Borg scores (visual analog scale) and anxiety (as assessed by the STAI-6 questionnaire). All of these variables are neutrally connected to respiratory discomfort in variable proportions, ${ }^{42}$ which rendered the tracking of their evolution an appropriate measure of treatment efficacy.

Effectively reducing anxiety in COPD constitutes a major goal of COPD-related dyspnea management, and in this respect, the present study showed particularly promising results. When monitoring anxiety and depression evolution before and after a comprehensive pulmonary rehabilitation program (PRP), Tselebis et $\mathrm{al}^{43}$ obtained a significant mean reduction of $-10 \%$ in STAI scores. In the present study, participants' STAI-6 score exhibited a significant mean reduction of over twice that amount after hypnosis, ie, $-23.6 \%$. Certainly, the conditions of experimentation between both studies were different (before and after a PRP vs one single treatment intervention), and no assessment of the minimally important clinical difference for the STAI has been conclusively established to date. Nonetheless, an anxiety reduction of this magnitude likely constitutes an argument in favor of the use of hypnosis as a successful device for the immediate modulation of COPD-related anxiety.

The efficacy of hypnosis for reducing an abnormally high respiratory rate had been previously demonstrated for a cohort of asthmatic patients. ${ }^{44}$ Additionally, Eren et $\mathrm{al}^{45}$ had compared midazolam use vs hypnosis for sedation in transesophageal echocardiography and found that oxygenation (as determined by $\mathrm{SpO} 2$ ) was more efficiently stabilized in the hypnosis group than in the midazolam group. Our findings confirmed that both of these hypnotic benefits could be extended to severe COPD patients: after a brief hypnotic intervention, participants experienced a diminishment in RR accompanied by an increase in $\mathrm{SpO} 2$. We posit that such a pattern, absent in the sham condition, could be interpreted as an optimization of respiratory quality. Notably, both of the aforementioned studies also registered a significant alleviation of anxiety (as determined by STAI scores). Put together, these findings would suggest that these three indicators are susceptible to change jointly during psychological intervention. Furthermore, Borg scores also decreased by a clinically significant amount, which was identified as 0.9 points in the literature. ${ }^{57,58}$

In a dyspnea alleviation study, Donnell et $\mathrm{al}^{46}$ evaluated whether the response to a sham aerosol was driven behaviorally or physiologically, and found that a reduction in dyspnea in response to sham placebo was unlikely. Our results seem to further uphold this idea. In our study, Borg scores and $\mathrm{SpO} 2$ levels improved after both hypnosis and sham interventions, confirming that the sham condition was effective in eliciting at least part of the effects produced by hypnosis. However, significant improvements in all four indexes, in a manner consistent with dyspnea and anxiety relief, were only found in the hypnosis condition.

In a recent study, Esser et $\mathrm{al}^{47}$ compared neural responses to the perception and anticipation of dyspnea between patients with COPD and healthy controls. They found that COPD patients showed enhanced activation in emotion-related brain regions vs controls (supplementarymotor area, sensorimotor cortices, thalamus, anterior cingulate cortex, dorsomedial prefrontal cortex, and insula). These differential activations, however, were present only during the anticipation phase, and not during the perception phase. Their findings led them to propose that such a biphasic activation pattern could justify the utilization of tailored psychological interventions for the treatment of dyspnea. We conclude that our protocol is one such intervention and that our findings strengthen the argument in favor of incorporating psychological tools and strategies into COPD management.

\section{Strengths and Limitations of This Study}

This study followed the current consensus regarding hypnosis security guidelines. It avoided the implementation of controversial techniques (eg, age-regression), and did not include patients suffering from any form of psychotic pathology. $^{48,49}$

Overall, hypnosis had a positive immediate impact on this sample of COPD patients, without entailing any adverse effects (none were reported). Our results were in line with previous studies, which show that the risks associated with hypnosis are virtually non-existent. ${ }^{48}$ Peerreviewed research on hypnosis safety suggests that the ratio of "negative" sensations following a hypnosis session is negligibly low. Most importantly, these rare negative sensations appear to be decorrelated from patient's hypnotic susceptibility, suggesting independence of hypnosis 49,50 and a misattribution of cause. ${ }^{51,52}$

Perhaps the most important limitation of this study was the impossibility of using a blind design. Not referring to hypnotic procedures explicitly as « hypnosis » has been shown to greatly limit their effectiveness, implying that 
some of the motivational and expectational elements associated with the process of hypnosis are fundamental for it to achieve its full range of effects. ${ }^{53}$ Thus, attempts at blinding the patient from the hypnotic procedure by not calling it hypnosis would have meant portraying a procedure all too different from the actual intervention we intended to evaluate. The distinctive feature of hypnosis is the administration of hypnotic suggestions: instructions preceded by a hypnotic induction, that target the patients' mental imagery and bodily consciousness with the purpose of producing perceptual and behavioral modifications. ${ }^{54}$ Our design was aimed at disentangling this particular component of hypnosis from other general elements present as well in relaxation and most forms of therapeutic intervention. ${ }^{55}$ While it would have been ideal to implement further questionnaires to quantify and identify concrete motivation and expectation differences between interventions, the patients' precarious condition prevented us from including additional steps that would have rendered session length prohibitive.

Another limitation was the impossibility of conducting a contrast between our dataset and another version of the dataset including the two dropped participants. As stated in the Results section, this was because data from the dropped participants were never available for analysis to begin with. Still, we estimated that the risk for attrition bias or cherrypicking was minimal and negligible. In terms of attrition bias, of the two dropped participants only one left the trial voluntarily: considering the observed significance thresholds and effect sizes, it was highly unlikely that the inclusion or exclusion of a single participant would derail the observed effects. As for skewing the data or inadvertently favoring a certain dataset, the risks were virtually nonexistent: the data of the dropped participants were never available for analysis, making it impossible for the investigators to favor one dataset over the other.

Further limitations involved the scope of this study, which was limited to observing the immediate effects of a hypnosis intervention on anxiety and respiratory quality. Its results only argue in favor of the implementation of the technique for transient anxiety management in COPD patients. Further research is needed to uphold claims of long-term benefits, estimated duration of positive effects, and whether these effects decay after the patient grows accustomed to hypnosis. Also, given the intricacies of the neural pathways of the respiratory network and its spatial organization, ${ }^{47}$ understanding to what extent and by what means the psychological and physiological effects of hypnosis interact with dyspnea perception is a daunting task that lies beyond the reach of this work. Answering these questions will require further efforts combining COPD research and experimental hypnosis research. Future directions should also include an evaluation of the efficacy of hypnosis complementary care by incorporating multiple hypnosis sessions into a Pulmonary Rehabilitation Program. Attempts should be made to replicate these results in a multi-center, large-sample study, as means to reinforce the validity of these and other potential findings. We hope the present work will be a seminal step towards the development of a long-duration hypnosis complementary protocol for the management (and selfmanagement) of chronic anxiety in COPD patients.

\section{Data Sharing Statement}

The anonymized data is available for free, upon request to the Centre Hospitalier de Bligny. The Centre Hospitalier de Bligny will only share the data to inquirers capable of respecting the conditions established by the Commission Nationale de l'Informatique et des Libertés for data protection (CNIL, https://www.cnil.fr/). Please address any questions to the corresponding author at hernan.anllo@cri-paris.org.

\section{Statement of Ethics}

This research was reviewed and approved by the national medical-ethical Committee of People Protection (CPP) of the Hotel Dieu Hospital, Ile-de-France, France (approval number: CPPIDF1-2019-ND75). It was conducted in accordance with the World Medical Association Declaration of Helsinki. All participants gave written informed consent.

\section{Acknowledgments}

We would like to thank Dr. Jean-Baptiste Meric, Mr. JeanLouis Di Tommaso and all the personnel of the Centre Hospitalier de Bligny for their tireless efforts in helping us make this study possible. We would like to specially thank Sandrine Brefort and Drs. Céline Pytlak, Françoise Haniez, Helene Jaillet, Mourad Saada and Christian Darne for their continuous support. We would also like to wholeheartedly thank all the patients who participated in the study, as well as those patients who gave us feedback on the hypnosis procedure.

\section{Funding}

This study was funded by the Bligny Hospital Center (CHB) and the Fondation pour les Soins Palliatifs (FSP). HA's contribution to this work was supported in part by 
the Japanese Society for the Promotion of Science (JSPS, GRANT NUMBER: 18F18307).

\section{Disclosure}

The authors declare no conflicts of interest, nor any competing interests.

\section{References}

1. Global Strategy for the Diagnosis, Management and Prevention of COPD, Global Initiative for Chronic Obstructive Lung Disease (GOLD) 2016 [homepage on the Internet]. Available from: http:// goldcopd.org/. Accessed October 5, 2020.

2. Han MK, Muellerova H, Curran-Everett D, et al. GOLD 2011 disease severity classification in COPD gene: a prospective cohort study. Lancet Respir Med. 2013;1(1):43-50. doi:10.1016/S2213-2600(12) 70044-9

3. Pumar MI, Gray CR, Walsh JR, Yang IA, Rolls TA, Ward DL. Anxiety and depression-Important psychological comorbidities of COPD. $J$ Thorac Dis. 2014;6(11):1615-1631. doi:10.3978/j. issn.2072-1439.2014.09.28

4. Hegerl U, Mergl R. Depression and suicidality in COPD: understandable reaction or independent disorders? Eur Respir J. 2014;44 (3):734-743. doi:10.1183/09031936.00193213

5. Kellner R, Samet J, Pathak D. Dyspnea, anxiety, and depression in chronic respiratory impairment. Gen Hosp Psychiatry. 1992;14 (1):20-28. doi:10.1016/0163-8343(92)90022-3

6. Maurer J, Rebbapragada V, Borson S, et al. Anxiety and depression in COPD: current understanding, unanswered questions, and research needs. Chest. 2008;134(4 Suppl):43S-56S. doi:10.1378/chest.08-0342

7. Di Marco F, Verga M, Reggente M, et al. Anxiety and depression in COPD patients: the roles of gender and disease severity. Respir Med. 2006;100(10):1767-1774. doi:10.1016/j.rmed.2006.01.026

8. Cafarella PA, Effing TW, Usmani Z, Frith PA. Treatments for anxiety and depression in patients with chronic obstructive pulmonary disease: A literature review. Respirology. 2012;17:627-638 doi:10.1111/j.1440-1843.2012.02148.x

9. American Thoracic Society Committee on Dyspnea. Mechanisms, assessment, and management: a consensus statement. American Thoracic Society. Am J Respir Crit Care Med. 1999;159 (1):321-340. doi:10.1164/ajrccm.159.1.ats898

10. Parshall MB, Schwartzstein RM, Adams L, et al.; American Thoracic Society Committee on Dyspnea. An official American Thoracic Society statement: update on the mechanisms, assessment, and management of dyspnea. Am J Respir Crit Care Med. 2012;185 (4):435-452. doi:10.1164/rccm.201111-2042ST.

11. Başoğlu M. Effective management of breathlessness: a review of potential human rights issues. Eur Respir J. 2017;49:1602099.

12. Tselebis A, Pachi A, Ilias I, et al. Strategies to improve anxiety and depression in patients with COPD: a mental health perspective. Neuropsychiatr Dis Treat. 2016;12:297-328. doi:10.2147/NDT. S79354

13. Smith SMS, Sonego S, Ketcheson L, et al. A review of the effectiveness of psychological interventions used for anxiety and depression in chronic obstructive pulmonary disease. BMJ Open Respir Res. 2014;1:e000042. doi:10.1136/bmjresp-2014-000042

14. Hynninen M, Bjerke N, Pallesen S, et al. A randomized controlled trial of cognitive behavioral therapy for anxiety and depression in COPD. Respir Med. 2010;104:986-994. doi:10.1016/j. rmed.2010.02.020

15. Lolak S, Connors G, Sheridan MJ, Wise TN. Effects of progressive muscle relaxation training on anxiety and depression in patients enrolled in an outpatient pulmonary rehabilitation program. Psychother Psychosom. 2008;77:119-125. doi:10.1159/000112889
16. Volpato E, Banfi P, Roger SM, et al. Relaxation techniques for people with chronic obstructive pulmonary disease: a systematic review and a meta-analysis. Evid Based Complement Alternat Med. 2015; (2015):628365.

17. Vickers A, Zollman C. ABC of complementary medicine. Hypnosis and relaxation therapies. BMJ. 1999;319:1346-1349. doi:10.1136/ bmj.319.7221.1346

18. Montgomery G, Sucala M, Baum T, Schnur JB. Hypnosis for symptom control in cancer patients at the end-of-life: a systematic review. Int J Clin Exp Hypn. 2017;65(3):296-307. doi:10.1080/ 00207144.2017.1314728

19. Brugnoli MP. Clinical hypnosis for palliative care in severe chronic diseases: a review and the procedures for relieving physical, psychological and spiritual symptoms. Ann Palliat Med. 2016;5(4):280-297. doi:10.21037/apm.2016.09.04

20. Kleinbub JR, Palmieri A, Broggio A, et al. Hypnosis-based psychodynamic treatment in ALS: a longitudinal study on patients and their caregivers. Front Psychol. 2015;6:822. doi:10.3389/ fpsyg.2015.00822

21. Brown D. Evidence-based hypnotherapy for asthma: a critical review. Int $J$ Clin Exp Hypn. 2007;55(2):220-249. doi:10.1080/ 00207140601177947

22. McBride J, Vlieger A, Anbar R. Hypnosis in paediatric respiratory medicine. Paediatr Respir Rev. 2014;15(1):82-85. doi:10.1016/j. prrv.2013.09.002

23. Anbar RD. Hypnosis for the treatment of functional respiratory disorders. In: Anbar RD, editor. Functional Respiratory Disorders. Respiratory Medicine. Totowa, NJ: Humana Press; 2012. doi:10.1007/978-1-61779-857-3_12

24. Elkington H, White P, Addington-Hall J, Higgs R, Pettinaric C. The last year of life of COPD: a qualitative study of symptoms and services. Respir Med. 2004;98(5):439-445. doi:10.1016/j. rmed.2003.11.006

25. Marteau T, Bekker H. The development of a six-item short-form of the state scale of the Spielberger State-Trait Anxiety Inventory (STAI). Br J Clin Psychol. 1992;31:301-306. doi:10.1111/j.20448260.1992.tb00997.x

26. Spielberger CD. Manual for the State-Trait Anxiety Inventory STAI (Form Y). Palo Alto, CA: Consulting Psychologists Press; 1983.

27. Gauthier L, Bouchard S. A French-Canadian adaptation of the revised version of Spielberger's state-trait anxiety inventory. Can J Behav Sci. 1993;25:559. doi:10.1037/h0078881

28. Smith I, Mackay J, Fahrid N, et al. Respiratory rate measurement a comparison of methods. Br J Healthc Assist. 2013;5(1):18-23. doi:10.12968/bjha.2011.5.1.18

29. Jubran A, et al. Pulse oximetry. In: Pinsky MR, editor. Applied Physiology in Intensive Care Medicine. Berlin: Springer Verlag; 2006.

30. Kendrick K, Baxi S, Smith R. Usefulness of the modified 0-10 Borg scale in assessing the degree of dyspnea in patients with COPD and asthma. J Emerg Nurs. 2000;26(3):216-222. doi:10.1016/S00991767(00)90093-X

31. $\mathrm{R}$ Core Team. R: A language and environment for statistical computing. Vienna, Austria: $\mathrm{R}$ Foundation for Statistical Computing; 2013. ISBN 3-900051-07-0. Availabe from: http:// www.R-project.org/. Accessed October 5, 2020.

32. Bates D, Maechler M, Bolker B, Walker S. Fitting linear mixed-effects models using lme4. J Stat Softw. 2015;67(1):1-48. doi:10.18637/jss.v067.i01

33. Agresti A. Categorical Data Analysis. second ed. Wiley; 2002.

34. Jaeger TF. Categorical data analysis: away from ANOVAs (transformation or not) and towards logit mixed models. $J$ Mem Lang. 2008;59(4):434-446. doi:10.1016/j.jml.2007.11.007

35. Pinheiro JC, Bates DM. Mixed-Effects Models in $S$ and SPLUS. New York: Springer; 2000. 
36. Bolker B, Brooks M, Clark C, et al. Generalized linear mixed models: a practical guide for ecology and evolution. Trends Ecol Evol. 2008;24(3).

37. Fox J, Weisberg S. An $\{R\}$ Companion to Applied Regression. Seconded. Thousand Oaks CA: Sage; 2011. Available from:: http:// socserv.socsci.mcmaster.ca/jfox/Books/Companion. Accessed October 5, 2020.

38. Lenth R. Least-squares means: the R package lsmeans. J Stat Softw. 2016;69(1):1-33. doi:10.18637/jss.v069.i01

39. Wagenmakers E, van der Maas H, Grasman R. An EZ-diffusion model for response time and accuracy. Psychon Bull Rev. 2007;14 (1):3-22. doi:10.3758/BF03194023

40. Schwarz G. Estimating the dimension of a model. Ann Stat. 1978;6:461-464. doi:10.1214/aos/1176344136

41. Morélot-Panzini C, Adler D, Aguilaniu B, et al. Breathlessness despite optimal pathophysiological treatment: on the relevance of being chronic. Eur Respir J. 2017;50(3):1701159. doi:10.1183/ 13993003.01159-2017

42. Hayen A, Herigstad M, Pattinson KT. Understanding dyspnea as a complex individual experience. Maturitas. 2013;76(1):45-50. doi:10.1016/j.maturitas.2013.06.005

43. Tselebis A, Bratis D, Pachi A, et al. A pulmonary rehabilitation program reduces levels of anxiety and depression in COPD patients. Multidiscip Respir Med. 2013;8:41. doi:10.1186/20496958-8-41

44. Morrison JB. Chronic asthma and improvement with relaxation induced by hypnotherapy. $J R$ Soc Med. 1988;81(12):701-704. doi:10.1177/014107688808101207

45. Eren G, Dogan Y, Demir G, et al. Hypnosis for sedation in transesophageal echocardiography: a comparison with midazolam. Ann Saudi Med. 2015;35(1):58-63.

46. Donnell CR, Lansing RW, Schwartzstein RM, Banzett R. The effect of aerosol saline on laboratory-induced dyspnea. Lung. 2017;195 (1):37-42. doi:10.1007/s00408-016-9971-3

47. Esser RW, Stoeckel MC, Kirsten A, et al. Brain activation during perception and anticipation of dyspnea in chronic obstructive pulmonary disease. Front Physiol. 2017;8:617. doi:10.3389/ fphys.2017.00617

48. Lynn SJ, Martin D, Frauman D. Does hypnosis pose special risks for negative effects? A master class commentary. Int J Clin Exp Hypn. 1996;44(1):7-19. doi:10.1080/00207149608416064

49. Brentar J, Lynn SJ. "Negative" effects and hypnosis: A critical examination. Br J Exp Clin Hypn. 1988;6:75-84.
50. Brentar J, Lynn SJ, Carlson B, Kurzhals R. Controlled research on hypnotic aftereffects: the post-hypnotic experience questionnaire. In: Bongartz W, editor. Hypnosis 175 Years After Mesmer. Konstanz, Germany: University of Konstanz Press; 1992:179-201.

51. Petersen I, Coe W, Crockford M, Decker S Hypnotic sequelae revisited. Paper presented at the 99th annual convention of the American Psychological Association; San Francisco, USA; 1991.

52. Sivec H, Lynn SJ Negative posthypnotic effects: the influence of prehypnotic experiences. Paper presented at the 44th Annual Meeting of the Society for Clinical and Experimental Hypnosis, Arlington Heigths; IL, USA; 1993.

53. Gandhi B, Oakley D. Does hypnosis by any other name smell as sweet? The efficacy of hypnotic inductions depends on the label « hypnosis ». Conscious Cogn. 2005;14:304-315. doi:10.1016/j. concog.2004.12.004

54. Terhune DB, Cleeremans A, Raz A, Lynn SJ. Hypnosis and top-down regulation of consciousness. Neurosci Behav Rev. 2017;81:59-74. doi:10.1016/j.neubiorev.2017.02.002

55. van Vliet LM, Godfried MB, van Deelen GW, et al. Placebo effects of nurses' communication alongside standard medical care on pain and other outcomes: a randomized controlled trial in clinical tonsillectomy care. Psychother Psychosom. 2020;89:56-58. doi:10.1159/ 000503904

56. Barabasz A, Olness K, Boland R, Kahn S, Editors. Medical Hypnosis Primer, Clinical and Research Evidence. New York: Routledge; 2010.

57. Khair R, Nwaneri C, Damico R, Kolb T, Hassoun P, Mathai S. The minimal important difference in Borg dyspnea score in pulmonary arterial hypertension; 2015.

58. Araujo Olivera A, Andrade L, Marques A. Minimal clinically important difference and predictive validity of the mMRC and mBorg in acute exacerbations of COPD. Eur Respir J. 2017;50:PA4705. doi:10.1183/1393003.congress-2017.PA4705

59. Stewart J. Hypnosis in contemporary medicine. Mayo Clin Proc. 2005;80(4):511-524. doi:10.1016/S0025-6196(11)63203-5

60. Eimer B. Inadvertent adverse consequences of clinical and forensic hypnosis: minimizing the risks. Am J Clin Hypn. 2012;55:8-31. doi:10.1080/00029157.2012.686071

61. Julian LJ. Measures of anxiety: state-trait anxiety inventory (STAI), Beck anxiety inventory (BAI), and hospital anxiety and depression scale-anxiety (HADS-A). Arthritis Care Res. 2011;63:S467-S472. doi:10.1002/acr.20561

\section{Publish your work in this journal}

The International Journal of COPD is an international, peer-reviewed journal of therapeutics and pharmacology focusing on concise rapid reporting of clinical studies and reviews in COPD. Special focus is given to the pathophysiological processes underlying the disease, intervention programs, patient focused education, and self management protocols. This journal is indexed on PubMed Central, MedLine and CAS. The manuscript management system is completely online and includes a very quick and fair peer-review system, which is all easy to use. Visit http://www.dovepress.com/testimonials.php to read real quotes from published authors. 